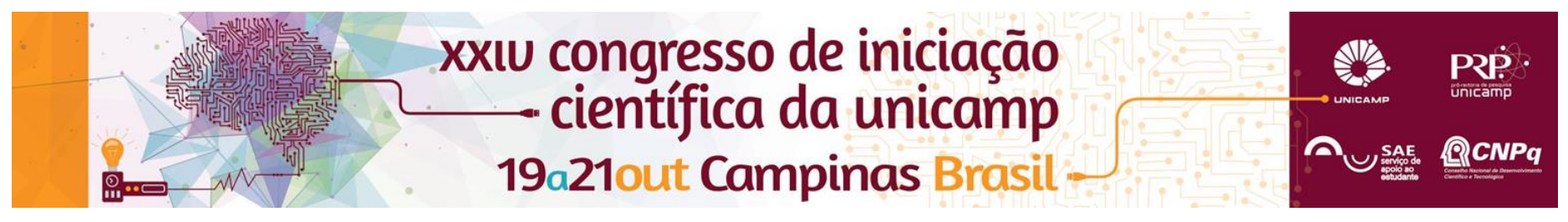

\title{
Epidemiologia da Dengue de 2014: Aspectos epidemiológicos e clínicos de pacientes atendidos no Hospital de Clínicas da UNICAMP
}

\author{
Vitor Y. Ueno*, Francisco H. Aoki.
}

\section{Resumo}

A dengue desde 1990 está se expandindo pelo Brasil, recentemente ocorrendo epidemias com repercussão nacional. O Hospital de Clínicas da UNICAMP, referência regional e nacional na saúde, atende um número considerável de pacientes suspeitos de dengue. Portanto, esse estudo tem como propósito coletar e analisar os aspectos clínicos, sorológicos e laboratoriais dos pacientes com suspeita de dengue no ano de 2014.

\section{Palavras-chave: \\ Dengue, Epidemiologia, UNICAMP.}

\section{Introdução}

No Brasil, desde 1990, o vírus da dengue vem se expandindo por todo o país. No HC da UNICAMP, as informações pertinentes dos pacientes com suspeita de dengue tratados na Unidade de Emergência Referenciada são registradas em fichas denominadas BAUs (Boletins de Atendimento de Urgência). Esse estudo pretende coletar dados e analisar as principais informações dos casos de dengue, abordando aspectos clínicos, epidemiológicos e laboratoriais de pacientes atendidos no PS do HC-UNICAMP.

\section{Resultados e Discussão}

Resultados Clínicos: 1146 pacientes haviam registros na base de dados. Ė relevante notar que os sinais e sintomas mais prevalentes são considerados genéricos, o que pode dificultar o diagnóstico da doença, sobretudo em vigência das atuais arboviroses. (Figura 1)

Resultados laboratoriais: dos 1146 pacientes, 893 não realizaram o teste IgM. É possível que a saturação do serviço hospitalar seja um motivo, e o registro nas BAUs de indicação de retorno à UBS para coleta de sorologia da maioria dos pacientes atendidos com suspeita de dengue. Os principais motivos encontrados para os resultados negativos são: confirmação de não ser dengue, e realização do teste antes do $6^{\circ}$ dia do início dos sintomas( teste positiva após $6^{\circ}$ dia) (Figura 2 )

Resultados de hemograma: foram encontrados dados de 126 pacientes adultos dentre os 1146 . Os demais 1020 adultos não tiveram seus hemogramas registrados. $A$ média de todos esses valores $(\mathrm{Hb}, \mathrm{Ht}$, Leucócitos e plaquetas) se encontra na Tabela 1, se situa dentro dos valores de referência de acordo com a faixa etária e sexo, o que condiz com o fato de a maioria dos pacientes atendidos não apresentarem sinais de Alarme ou Choque', classificados de acordo o MS. (Tabela 1)

Tabela 1: Hemograma - Média dos valores

\begin{tabular}{|l|l|l|l|l|}
\hline & $\mathrm{Hb}(\mathrm{g} / \mathrm{dL})$ & $\mathrm{Ht}(\%)$ & Leucócitos & Plaquetas \\
\hline Homem & 14,42 & 42,13 & 6193 & $172 \mathrm{mil}$ \\
\hline Mulher & 13,19 & 38,59 & 6236 & 211,66 mil \\
\hline VR & $\mathrm{H}: 13,3-16,7$ & $\mathrm{H}: 39-50$ & $3700-9500$ & $150 \mathrm{mil}-400 \mathrm{mil}$ \\
& $\mathrm{M}: 11,8-16,7$ & $\mathrm{M}: 36-44$ & & \\
\hline
\end{tabular}

Figura 1 Sinais e Sintomas $\mathbf{n}=\mathbf{1 1 4 6}$ pacientes

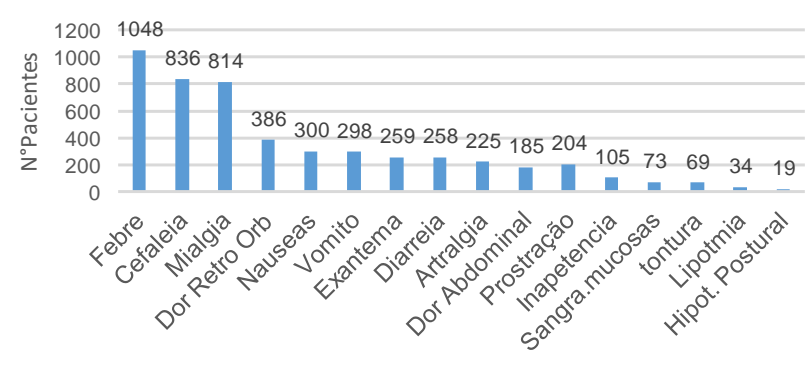

Figura 2

IgM Realizados $\mathrm{n}=\mathbf{2 5 3}$ pacientes

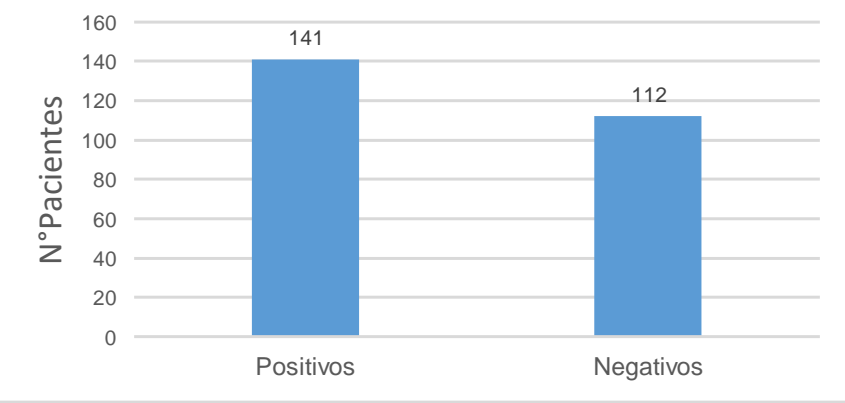

\section{Conclusão}

Mesmo o HC-UNICAMP sendo um hospital terciário e de complexidade, é elevado o número de atendimentos menos graves. É fundamental que as UBSs se tornem referência para a população quanto ao Atendimento Primário na suspeita de dengue, e a procura pelos serviços terciários só seja necessário no caso de complicações mais graves.

\section{Agradecimentos}

Agradecimentos ao orientador Francisco H. Aoki, e ao $\mathrm{PIBIC/CNPq}$.

\footnotetext{
${ }^{1}$ Ministério da Saúde. Secretaria de Vigilância em Saúde.Diretoria Técnica de Gestão. Dengue: diagnóstico e manejo clínico - adulto e criança. $4^{\circ}$ ed. Brasília: Ministério da Saúde, 2011,21,44.
} 